\title{
Francisco Fabra y su relación del colegio de Tarija y sus misiones (1770) para el P. Pedro de Calatayud
}

\author{
Francisco Fabra and his relationship with the school of Tarija and his \\ missions (1770) for Father Pedro de Calatayud \\ Carlos A. Page*

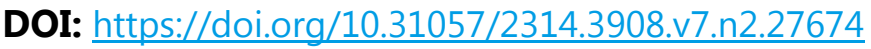

Resumen: Como venimos publicando hasta el momento, el documento que presentamos en esta oportunidad, es uno de los 12 conocidos e inéditos, que presentaron diversos jesuitas de la provincia del Paraguay al P. Pedro Calatayud para facilitarle la tarea en la composición de una historia del Paraguay, de la que solo pudo esbozar un borrador. En este caso en particular es un texto, como el título lo indica, de un colegio que tuvo especial gravitación en la creación y desarrollo de las misiones de chiriguanos y especialmente de chiquitos, esa gran esperanza misional que significó para los jesuitas de la primera mitad del siglo XVIII.

Palabras clave: Francisco Fabra, Pedro de Calatayud, Colegio de Tarija, Historia de la provincia jesuítica del Paraguay.

Abstract: As we have been publishing so far, the document we present on this occasion is one of the 12 acquaintances presented by various Jesuits from the province of Paraguay to Fr. Pedro Calatayud to facilitate the task in the composition of a history of Paraguay, of which he could only sketch a draft. In this particular case, it is a text, as the title indicates, of a school that had special gravitation in the creation and development of the missions of Chiriguanos and especially of children, that great missionary hope that meant for the Jesuits of the first half 18th century

* CIECS-CONICET/UNC· E-mail: capage1 @ hotmail.com https://orcid.org/0000-0003-4708-5243 
Keywords: Francisco Fabra, Pedro de Calatayud, Tarija College, History of the Jesuit province of Paraguay.

Recibido: 21 de julio de 2019.

Evaluado: 4 de noviembre de 2019.

\section{Carlos A. Page}

Arquitecto y Doctor en Historia. Investigador del CONICET, con estudios posdoctorales en el CSIC (España) y en el CNR (Italia). Profesor de posgrado en la UBA y la UNaM. Miembro del Comité Científico del SIEJ (Société Internationale d'Etudes Jésuites) e investigador extranjero del grupo Jesuítas nas Americas (CNPq-Brasil) y el CLEPUL (Centro de Literaturas e Culturas Lusófonas e Europeias da Faculdade de Letras da Lisboa). Dirige el programa "Antiguos Jesuitas en Iberoamérica" (CIECS/CONICET-UNC) y es investigador del Instituto de Teoría e Historia del Arte "Julio E. Payró" (FFyL-UBA). Fundador-Director de la revista científica "IHS. Antiguos jesuitas en Iberoamérica". Publicó alrededor de 300 artículos en revistas científicas y de divulgación en Iberoamérica, Estados Unidos y Europa. Se suman más de 30 libros. Sitio web http://www.carlospage.com.ar/ 


\section{El autor y la relación}

El P. Francisco Fabra nació en la población valenciana de Villar del Arzobispo, el 3 de abril de 1723. Anteriormente, la pequeña localidad, se llamó Villar de Benaduf, siendo reconquistada a los musulmanes en el siglo XII y pasando a manos del arzobispo de Valencia, que la donó para ser repoblada por cristianos. En 1795, es decir mucho después que naciera Francisco, el rey Calos IV, sustituyó Benaduf y le otorgó el título de villa real.

Nuestro personaje ingresó a la provincia jesuítica de Aragón a mediados de 1739, arribando a Buenos Aires el 15 de julio de 1745 (Storni, 1980, 94) en la nutrida expedición de los PP. Diego Garvia y Juan José Rico, quienes regresaron en tres naves: "Santiago el perfecto", a cargo del maestre José de Egaña y "El Héctor", bajo el mando de Melchor Delgado. Una tercera embarcación partió de España completando esta flota, el "Duque de Chartres", que traía consigo una expedición chilena y que tuvo el infortunio de naufragar y morir la mayoría de los jesuitas que iban a bordo (Page, 2007, p. 47). Compartieron el viaje dos de los jesuitas que se reencontrarían en el exilio con el mismo objetivo de ayudar al P. Calatayud. Eran los PP. Lorenzo Casado y José Quiroga, pero por cierto, también viajaron algunos otros que alcanzaron relevancia como José de Robles, quien junto a Muriel fueron los últimos procuradores a Europa, además de provincial en el exilio; o el mártir Santiago Herrero, que tanto mencionan sus contemporáneos en diversos textos. En la relación de embarque se describe al joven Fabra de 21 años, como: "delgado, algo moreno, poca barba, cejas pobladas, ojos y pelo negros", agregando que venía de Cervera, Cataluña, de donde salió el 13 de diciembre (Pastells, 1948, VII, 580).

Profesó su cuarto voto en el colegio de Belén de Buenos Aires en el verano de 1757 (Storni, 1980, p. 94). Colegio y Casa de Ejercicios que para la expulsión aún no habían concluido con el edificio y los encontraría a todos los jesuitas en la espera para embarcarse al exilio.

El P. Fabra es un personaje muy poco conocido, inexistente en la extensa historiografía chiquitana. Ni siquiera se lo menciona en las Anuas, y en los catálogos del ARSI figura en el colegio de Tarija en 1753, con tres años de Filosofía y uno de Teología, siendo provincial el P. Barreda y rector de aquel colegio el P. Simón Bailina ${ }^{1}$. En el siguiente y último catálogo de 1763, aparece como compañero de misión, en este caso del P. Andrés Carranza, en el colegio de Salta, cuando era rector el P. Andrés Aztina ${ }^{2}$.

La expulsión, lo sorprendió en el colegio de Tarija el 23 de Agosto de 1767, cuando era rector el P. Franciso Frasset ${ }^{3}$ y él su procurador. La operación militar la llevó a cabo el flamante presidente de la Real Audiencia de Charcas don Juan Victorino Martínez de Tineo. A su vez éste ordenó para llevar a cabo la confiscación y arresto del colegio de Tarija al corregidor Tomás José de Herrera. Hace tiempo publicamos una relación anónima de los pormenores de aquellos aciagos días (Page, 2011, pp. 253-309), donde se destaca una variada información sobre la situación del colegio, a modo de Carta Anua parcial, pero en una segunda parte nos relata el viaje a Buenos Aires. Previamente el corregidor, después de tomar la filiación de cada uno, los encerró en un cuarto, excepto a

\footnotetext{
${ }^{1}$ Paraguar 6, Cat. Trien. 1703-1762, f. 358v.

${ }^{2}$ Ibid., f. 369.

${ }^{3}$ El Padre Frasset nació en Palma de Mallorca el 11 de enero de 1714. Ingresó a la Compañía del Paraguay en 1734 y al año siguiente arribó a Buenos Aires. Sus últimos votos los hizo en 1747. De Tarija pasó a su exilio en Europa, donde falleció en Faenza el 4 de junio de 1782 (Storni, 1980, p. 105).
} 
los PP. Frasset y Fabra, para que participaran de la confección del inventario, desde el edificio hasta los libros ${ }^{4}$. Luego se los reunió en el convento de San Francisco, de donde partieron el 27 de octubre, para arribar a Buenos Aires el 23 de febrero del año siguiente, no sin sufrir los padecimientos que implicaban los casi 2.000 kilómetros que recorrieron, donde por ejemplo falleció el P. Azua en Yaví y se le sumaron en el trayecto jesuitas de otras ciudades y misiones.

Al llegar a Buenos Aires fueron embarcados en la fragata de guerra "La Esmeralda" , junto a jesuitas de Asunción, Corrientes, Santa Fe, Salta, los poblados del Chaco, Santiago del Estero, Catamarca, Tucumán, La Rioja, San Juan, San Luis, Mendoza y algunos pocos de Córdoba, Buenos Aires y Potosí, en un total de 155 jesuitas y de los cuales obviamente, estaban los del colegio de Tarija, con su rector, ya mencionado, además de nueve sacerdotes y dos coadjutores ${ }^{6}$.

Poco y nada sabemos de su vida en el exilio. Solo que muere en Castrocaro Terme, en Forlí, el 10 de marzo de 1789 (Storni, 1980, p. 94). Es decir 22 años confinado a los avatares de los expulsos y antojos de la corona española.

El documento, que firma el 10 de mayo de 1770, es bastante detallado, en la medida de su corta extensión, marcando la preponderancia e iniciativa de la fundación del colegio de Tarija por parte de la esposa del marqués de Tojo, Juana Clemencia de Ovando, cosa que en las Cartas Anuas le dan el crédito a su marido. Pero aquí queda bien explícito la importancia de Juana, al ser vecina de Jujuy y heredera de sus ricos padres, y él un español recién llegado (chaperón). El montañez quedó viudo sin haber concebido un hijo, por lo que heredó, títulos y bienes de su esposa, pero con el cargo de cumplir el deseo de ella de que parte de sus bienes pasaran a la Compañía de Jesús. El P. Fabra relata con precisión los hechos que se sucedieron a partir de los "fundadores" y las circunstancias que llevaron a Juana a tomar la decisión de ayudar a los jesuitas, seguramente ante el impacto que le debe haber causado el martirio de los PP. Solinas y Ortiz de Zárate ${ }^{7}$.

Posteriormente describe la región, señalando en ella la muerte de seis mártires jesuitas, aunque fueron algunos más. Menciona los dos poblados de chiriguanos que fundaron los jesuitas: Concepción y Presentación. De este último relata una conocida anécdota del P. José Francisco de Arce, cuando llega a Santa Cruz y el gobernador lo incita a dejar a los chiriguanos y dedicarse a los chiquitos. Arce no descuidó a los chiriguanos y obtuvo el permiso de su superior, para emprender la misión, fundando el primer pueblo entre los chiquitos. Pero las dificultades crecieron con los avances portugueses que enfrentaron los jesuitas junto con los chiquitos, como al igual que los constantes atropellos de los chiriguanos durante cinco años, con nuevas pérdidas de vidas.

\footnotetext{
${ }^{4}$ Archivo Nacional de Chile, Jesuitas V. 149, pieza 11.

${ }^{5}$ La fragata de guerra "La Esmeralda", de alrededor de 30 cañones, estuvo bajo la advocación de Santa Lucía Mártir, siendo botada en 1752. Estuvo a cargo del capitán de fragata don Mateo Collado Nieto desde 1766, llegando a Montevideo en diciembre y de allí al Callao para regresar a Montevideo con las fragatas "Liebre" y "Venus". Zarpó de Buenos Aires con los jesuitas, el 8 de abril de 1768, regresando a Cádiz el 9 de setiembre.

${ }^{6}$ Eran ellos, además del rector y el procurador, los PP. Antonio Garau, Bartolomé Franco, Antonio Paris, Cayetano Torres, Francisco Fabra, Mateo Solares, Miguel Pardo, Ramón Salat, Simón Hernáez (los dos últimos de la reducción de chiriguanos) y Agustín Azua (que muere en el viaje), los HH. Pedro Haro y Antonio Benigno Muñoz (Pastells, 1949, VIII, p. 1.302).

${ }^{7}$ Sobre estos mártires, de los que se ha iniciado causa de canonización, ver (Bussu, 2003).
} 
Continúa con las actividades propias del colegio, en cuanto a la enseñanza de la gramática y latín, que se impartía a los niños, que no solo eran de Tarija. Otros jesuitas del colegio se dedicaban al ministerio de las misiones volantes, dos veces al año, extendiéndose el recorrido hasta el océano Pacífico. También dos misioneros atendían la misión de chiriguanos, en tanto que contaban con las congregaciones de la Buena Muerte y de los Corazones de Jesús y de María, además de organizar diversas y variadas fiestas religiosas que incluían a Nuestra Señora de Tariquea, describiendo la historia de esta particular imagen que presidía la iglesia del colegio. Se refiere a su vez a una propiedad con muchos cuartos, que habían adquirido para los Ejercicios Espirituales

Los gastos del colegio, además de las misiones y los Ejercicios, se solventaban con donaciones y dos estancias, una de ganados y otra de viñas. En ella había asalariados, indios yanaconas y africanos esclavizados, de los cuales describe la relación que sostenían entre ellos y los jesuitas. Concluye manifestando el perjuicio que la expulsión causó a los vecinos de Tarija y apenas unas líneas sobre los últimos días que vivieron en aquella ciudad.

\section{Relacion del Colegio de Tarija y sus missiones de la Provinci $i^{\mathrm{a}}$ del Paraguay ${ }^{8}$.}

Fue su fundación el año de $1682^{9}$, su Fundadora Doñ ${ }^{\mathrm{a}}$ Juana Clemencia de Obando ${ }^{10}$, vecina, é hija de la Villa de Tarija, mujer rica, y hazenta en Tarija en Viña, y otras tierras de pan llebar, y juntament $\mathrm{e}^{\mathrm{e}}$ vecina de la ciudad de San Salvador de Jujui de la Provinci ${ }^{\mathrm{a}}$ de tucuman, hazendada de dicha Provinci $i^{\mathrm{a}}$ en tierras, ganados y en dos encomiendas de indios de los Pueblos de casabindo, y cochinoca ${ }^{11}$, casada con un caballero, ó chapeton

\footnotetext{
${ }^{8}$ Al pie de página y con otra letra se lee "Esta Relacion es del Padr Juan Nicolas Araoz misionero del partido de la Ciudad de Tarija tocante al Reyno del Peru". Pues, el P. Araoz (San Miguel de Tucumán, 1706-Faenza, 1789), si bien estuvo varios años en Tarija, para la expulsión se encontraba en el colegio de Santiago del Estero, como rector (Page, 2011, p. 117). El documento tiene la rúbrica de Francisco Fabra (Archivo Histórico del Santuario de Loyola, Misiones, Paraguay, Documentos históricos 1570-1770. Caja 19/1, Legajo 10).

${ }^{9}$ La escritura la otorgó en Jujuy, donde se encontró con cinco Padres que habían partido de Córdoba rumbo a Tarija. Llegaron acompañados por los donantes el 4 de marzo de 1691, luego de recorrer 300 leguas en cinco meses.

${ }^{10}$ Juana Clemencia Bermúdez de Ovando era hija del encomendero Pablo Bernárdez de Ovando, poderoso terrateniente del norte de la gobernación del Tucumán y de Ana María de Mogollón y Orozco. Contrajo matrimonio con Campero en 1679 a los 10 años de edad por una alianza familiar que había promovido su albacea el vicario de Jujuy, Pedro Ortiz de Zárate. Lo hizo para salvar la fortuna del padre de la niña, primo de Ortiz de Zárate, que estaba acechada por su esposa Ana María Mogolón y su nuevo marido Pedro de Santiesteban. De tal forma que las inmensas riquezas de Pablo Bernárdez de Ovando, compuesta de un conjunto significativo de propiedades que se extendían desde Tarija hasta Tucumán, como la estancia de Yaví, donde residía, y la encomienda más importante de la gobernación del Tucumán, pasó a quedar a disposición del flamante matrimonio. Un retrato de la pareja se encuentra en el retablo principal de la iglesia de Cochinoca; lo preside Nuestra Señora de la Almudena y está atribuido al artista Mateo Pizarro y fechado en 1693. Clemencia murió en 1690, a los 23 años, pasando sus bienes a su marido (Page, 2010, p. 25).

${ }^{11}$ Luego de la victoria española en la batalla de Cochabamba de 1538, los indígenas de Casabindo y Cochinoca fueron entregados en encomienda a Martín Monje y Juan Villanueva, vecinos de Charcas. Pasaron luego al hijo de Monje y posteriormente a Cristóbal de Sanabria. Años después, y en base a la resistencia indígena fueron otorgados en merced a don Pablo Bernárdez de Ovando en 1654, quien realizó un primer padrón (Palomeque y Tedesco, 2014) Bernárdez o Velásquez de Ovando se casó con Ana María de Mogollón y Orozco, siendo padre de Juana Clemencia.
} 
(que se dize) Montañez llamado $\mathrm{D} o^{\mathrm{n}}$ Juan Campero y Herrera ${ }^{12}$; tenian los $\mathrm{P} a d r^{\mathrm{es}}$ de $\mathrm{D} o \tilde{n}^{\mathrm{a}}$ Juana (hija unica, y heredera de ellos de las encomiendas, tierras, y haziendas referidas) su asiento, ó casa estable en un parage llamado Yabí ${ }^{13}$ casi raya del fin de la Provinci $i^{\text {a }}$ del tucuman, y como principio de la Provinci $i^{\mathrm{a}}$ de chichas $^{14}$, a quien pertenece la Villa de Tarija, ó es la capital de la Provinci ${ }^{a}$ de chichas, por estar en ella cavildo, y regimiento de españoles. En Yabí vivía Doñ ${ }^{\mathrm{a}}$ Juana con su marido Do $o^{\mathrm{n}}$ Juan Joseph, quando vinieron dos Jesuitas ${ }^{15}$ del Colegio de Salta ${ }^{16}$ á correr la mission por los Pueblos de tilcara, uquía, Humaguaca, Casabindo, y cochinoca y llegaron con su empleo á Yabí, donde avia y ay Capilla, fueron bien recibidos de Campero, y su mujer, quien fue la primera vez, que vio Jesuitas, y recibió el beneficio de sus ministerios, y desde luego se aficiono á ellos, y trato con su marido de fundar colegio en la villa de Tarija, el Marido, que era buen christiano assintió á ello, comunico el pensamient $t^{\circ}$ de su mujer á los missioneros, estos respondieron lo que debian, de que diesen sus merce $e^{\text {des }}$ parte al Padr ${ }^{\mathrm{e}}$ Provincia ${ }^{1}$; assi se hizo, é hizieron todas las otras diligencias hasta executar la fundacion; la Seño ${ }^{\text {ra }}$ Doñ $\tilde{n}^{\mathrm{a}}$ Juana dixo, que

\footnotetext{
12 Juan José Fernández Campero de Herrera nació el 16 de septiembre de 1645 en Abionzo, Valle de Carriedo, montañas de Burgos, en España y falleció en 1718. Ya en América, contrajo matrimonio con Juana Clemencia de Ovando, hija de un poderoso encomendero, quien al intentar dar a luz murió con el pequeño, quedando su esposo como único heredero de una cuantiosa fortuna. Se casó nuevamente con Josefina Gutiérrez de la Portilla, con quien tiene dos hijas. El rey le otorgó el título de marqués del Valle de Toxo en 1708 y con el tiempo alcanzó los de caballero de la Orden de Calatrava y Maestre de Campo. Fue encomendero de los pueblos de Cochinoca y Casabindo, donde sus doctrineros los asistían en educación en la fe católica. En esos pueblos construyó iglesias con costosos tabernáculos y ornamentos para las celebraciones. Su devoción hacia los jesuitas lo llegó a solventar los gastos que demandaba el colegio de Tarija, a través de la donación de ocho cosechas de vino de su hacienda de la Angostura, un solar para edificar la iglesia, tierras de sembradío y demás bienes. Este colegio fue estratégico para fomentar las misiones de chiriguanos, tobas y chiquitos (Pastells, 1923, IV, p. 445). Fue su gloria haber mantenido no solo el colegio de Tarija y las misiones de chiquitos a las que proveía de ropa, vino, harina y regalos para los sacerdotes y ropa de la tierra e instrumentos de labranza para los indios. Su actitud se resume en un significativo hecho, el de haberse negado a participar en la guerra contra los indios que comandó el gobernador Urizar de Arespacochaga. Fue intimado por la Audiencia, el gobernador y el Cabildo de Jujuy que no lograron quebrantar su obstinada actitud y que concluyeron con el embargo de su encomienda. (Page, 2010, p. 24).

${ }^{13}$ Yabí se encuentra a unos 200 kilómetros de Tarija, en la actual provincia de Jujuy, limitando con Bolivia. Fue paso obligado del Río de la Plata a las minas de Potosí y como señala Fabra, asentamiento del marquesado de Tojo. La capilla, a la que se refiere el texto, fue consagrada en 1680 y dedicada a San Francisco, siendo su construcción concluida en 1708 por Juan José Fernández Campero de Herrera, quien además dotó al templo de los retablos y pinturas altoperuanas que aún se conservan (Campero, 2008).

${ }^{14}$ La antigua provincia de los chichas (epónimo del pueblo chicha) se ubicaba al sur y suroeste de Bolivia y extremo norte de Argentina. Fue conquistada por los Incas en tiempos de Túpac Inca Yupanqui, y la primera expedición española fue la que condujo Diego de Almagro en 1536, quienes llegaron a su capital Tupiza.

${ }^{15}$ Fracasadas las incursiones militares contra los indígenas, el gobernador Fernando de Mendoza Mate de Luna y el obispo fray Nicolás de Ulloa, resolvieron que los jesuitas debían nuevamente emprender la "conquista espiritual del Chaco”. El provincial Tomás de Baeza escogió para la misión a los PP. Diego Ruiz y Juan Antonio Solinas, además del H. Silvestre González, a quienes se sumó el sacerdote don Pedro Ortiz de Zárate quien incluso financió la campaña. Partieron de Salta a Uquía y luego el Valle de Senta, en una larga peregrinación que concluyó con la muerte de Solinas y Ortiz de Zárate de manos de los tobas el 27 de octubre de 1683 (Furlong, 1939, pp. 73-75).

${ }^{16}$ Los primeros jesuitas en arribar a Salta en 1585 fueron los PP. Francisco de Angulo y Alonso Bazana, hospedándose en la casa de don Hernando de Lerma. Tres años después llegó el P. Juan Romero y alquiló una modesta casa como residencia, que por falta de sustento y de personal que la atendiera, fue clausurada en 1602. La residencia definitiva se abrió en 1612, gracias a la donación del presbítero Alonso de Osuna y en 1624 pasó al rango de colegio. A partir de entonces se hicieron varias misiones a las regiones fronterizas, tanto a los tonocotes del este como a los calchaquíes del oeste. El edificio del colegio e iglesia quedó destruido en 1635 tras una creciente del río Arias, pero con el tiempo se reconstruyó (Furlong, 1939, pp. 912).
} 
queria se fundasse esse colegio principalment $\mathrm{p}^{\mathrm{e}} \mathrm{r}^{\mathrm{a}}$ la conversion de los indios infieles chiriguanos; poco despues de esto murió sin sucesion de hijo alguno, dexando por heredero á puerta cerrada á su marido con el cargo de fundar dicho colegio, y par ${ }^{\mathrm{a}}$ el fin dicho, y encargo de que a los missioneros de indios infieles, les hiziesse socorro anual de harina, y vino, $a^{\mathrm{a}}{ }^{\mathrm{a}}$ missas; todo lo cumplio $\mathrm{D} o^{\mathrm{n}}$ Juan Joseph Campero; quien viéndose rico se hizo caballero del Abito de Santiago, y á titulo Marquez de toxo (nombre de un vallecito en la Provinci $i^{\mathrm{a}}$ de Chichas, que heredo de su muger difunta) no $\sin \mathrm{q} u e \operatorname{los} \mathrm{P} a d r^{\mathrm{es}}$ Jesuitas á título de agradecidos, no coopeasen á solicitarle, y facilitarle los dos dichos títulos [f. $1 \mathrm{v}]$ títulos, que los lleno con bondades, y mucha piedad christiana, amor, y reconoscimiento a la Compañ ${ }^{a}$ de Jhesús, y a su colegio de Tarija, quedando tambien con el titulo de fundador, y como á tal, á el, y á sus sucesores se les dá la vela el día de San Miguel Archangel, Patron de dicho colegio de Tarija, en señal de agradecimiento.

Viendose sin sucession $\mathrm{D} o^{\mathrm{n}}$ Juan Joseph Campero se caso con Don $\tilde{n}^{\mathrm{a}}$ Phelipa Herrera $^{17}$, natural de la ciudad de Oruro en el Peru, en ella tuvo dos hijas, la $2^{\mathrm{a}}$ murió niña, la $1^{\mathrm{a}}$ y mayor llamada Don $\tilde{n}^{\mathrm{a}}$ Manuela heredo el marquesado, y todos los bienes de la casa de yabí, casó con $\mathrm{D} o^{\mathrm{n}}$ Alonzo Martiarena del Barranco, noble viscaino, tuvieron larga sucesion y el Marquez presente es su hijo ${ }^{18}$, y heredero, y aunque dichos herederos de la

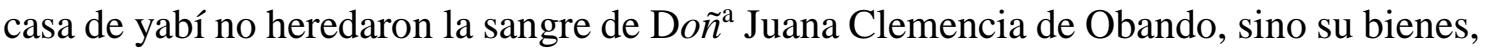

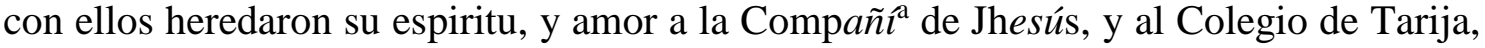
que siempre le han visto como á hijo, á obra suya este colegio es el mas glorioso de toda la Provinci $i^{\mathrm{a}}$ del Paraguay, porque tiene mas campo par ${ }^{\mathrm{a}}$ sus glorias missioneras, y demas ministerios entre fieles, é infieles, azia al poniente hasta el mar del sur entre fieles; al Norte también entre fieles por todo el corregimient $t^{\circ}$ de Pilaya y Paspaya, que aora llaman de Sinti, al Sur tambien entre fieles, no por tantas leguas, como por el Norte; al oriente, poco entre fieles, mucho entre infieles chiriguanos, y otras Naciones, y según la mente de su Fundador, principal campo; como que assi ha sido; pues en el cuenta 6 martyres; el $1^{\circ}$ $\mathrm{P} a d r^{\mathrm{e}}$ Lucas Caballero, $2^{\circ} \mathrm{Herman}^{\mathrm{o}}$ Norberto Romero muertos por los infieles chiquitos al fin de siglo passado, ó al principio de este, que no me acuerdo puntualment $t^{\mathrm{e}} ; 3^{\circ} \mathrm{P} a d r^{\mathrm{e}}$ Bartolome Blende, $4^{\circ} \mathrm{Padr} r^{\mathrm{e}}$ Joseph Arce muertos por los infieles Payaguas el año de 15 de este siglo; $15^{\circ}$ el Padr Julian Lizardi muerto por los chiriguanos el año de 35 de este siglo; $6^{\circ}$ el Padr ${ }^{\mathrm{e}}$ Agustin Castañares muerto por infieles Abuchetas ${ }^{19}$ el año de 44 de este $\operatorname{siglo}^{20}$; desde su fundacion se aplicaron los de este colegio a la conversion de los infieles,

\footnotetext{
${ }^{17}$ Acá Fabra comete un error, en realidad y como mencionamos antes se casó con Josefina Gutiérrez de la Portilla y Fernández, nacida en Cusco y fallecida en la residencia de Yavi el 10 de julio de 1727. Sus padres fueron el general Felipe Antonio Gutiérrez de la Portilla, caballero de Santiago, y Josefa Fernández Caballero. Fernández Campero se casó el 26 de febrero de 1708 y tuvo dos hijas: Manuela Micaela Ignacia Fernández Campero y Gutiérrez (Santa Rosa de Tojo, 1710-1759) y Josefa Fernández Campero y Gutiérrez. ${ }^{18}$ Efectivamente, Manuela, heredó el marquesado, y contrajo matrimonio con el capitán Alejo Martiarena del Barranco (Villa del Pasajes, Guipúzcoa, 1693-actual territorio argentino, 1758), teniendo 5 niñas y un varón, llamado Juan José Gervacio Martiarena del Barranco y Fernández Campero (1754-1784), que seguirá con el marquesado, al igual que su esposa e hijos.

${ }^{19}$ Según la clasificación del P. Camaño, hacia mediados del siglo XVIII, los abucchetas eran parte de la familia de los mataguayos, junto con los matacos, hueshuos, pesatupes e imacas (Rossi, 2007, p. 42).

${ }^{20}$ El P. Francisco Lucas Cavallero, nació de Villamuera de la Cueza, Palencia, falleciendo entre los chiquitos el 18 de setiembre de 1711. Alberto Romero fue pretendiente de la Compañía de Jesús, siendo asesinado por los zamucos el 1 de octubre de 1719. Bartolomé De Blende nació en Brujas, Flandes, muriendo de manos de los payaguás en setiembre de 1715. José Francisco de Arce nació en Santa Cruz de la Palma, Tenerife, y falleció en Pataguá en diciembre de 1715. Julián Lizardi era de Asteau, Guipúzcoa, muriendo en el Chaco el 17 de mayo de 1735, siendo el único al que se le inició una causa de beatificación. Agustín Castañares era natural de Salta, llegando a ser superior de chiquitos y falleciendo en el Chaco el 15 de setiembre de 1744. Le faltó mencionar a los PP. Antonio Guasp que era natural de Palmas de Mayorca y
} 
primero chiriguanos; tuvieron ó fundaron entre ellos dos Pueblos, vno en el valle llamado taraquea, y ahora tariquea con el titulo de la Concepcio ${ }^{\mathrm{n}}$ de Nuestra Seño ${ }^{\mathrm{ra}}$, el otro en el valle llamado Carurutí con el título de la Presentacion de Nuestra Seño ${ }^{\text {ra }}$, distante vn Pueblo de otro como 20 leguas entre serranías ${ }^{21}$.

Passando de este Pueblo de la Presentación ${ }^{\mathrm{n}}$ de Nuestra Seño ${ }^{\mathrm{ra}}$, el Padr ${ }^{\mathrm{e}}$ Joseph $\mathrm{Arze}^{22}$ á la ciudad de San ${ }^{\text {ta }}$ Cruz de la Sierra, á pedir al Governad ${ }^{\text {or }}$ de essa ciudad la libertad de vn indio infiel chiriguano, a quien le tenia el Governador en prisión, despues de condescender con el $\mathrm{Padr} r^{\mathrm{e}}$, le dixo, que dexando á los chiriguanos, que eran indios protervos, emprehendiesse la converssion de los chiquitos, que eran dociles le respondiendo al $\mathrm{Padr} r^{\mathrm{e}}$ lo que debia, escribió al Governado ${ }^{\mathrm{r}}$ al $\mathrm{P} a d r^{\mathrm{e}}$ Provincial del Paraguay, y obtenida [2] obtenida la licencia, emprendio el Padr Joseph Arce essa mission con otro sugeto del colegio de tarija, con avios, y dependencia de este colegio, en tan buena razón, que correspondio el fruto al trabajo ${ }^{23}$, se fueron multiplicando Pueblos, y sujetos por la via de Tarija, de donde les iban los socorros de la casa de yabí, y de otras limosnas; no se desampararon los dos Pueblos dichos de los chiriguanos, hasta que pasados, casi 20 años, viendo el poco, ó ningun fruto en ellos, y como perdiendo la esperanza de fruto; el superior con sus 3 compañeros (como que era tambien superi ${ }^{\text {or }}$ de los Pueblos nuevos de chiquitos) passo alla; y adjudico vna estancia de algun ganado perteneciente a los dos Pueblos dexados de chiriguanos, a la mission, á Pueblos de chiquitos, esta estancia esta en el valle, que llaman Salinas ${ }^{24}$, y en verdad le viene bien al Hombre, porque ay vn serro de sal, en guijarro, que con bareta y tiros de polvora, se saca en pedazos, ó trozos de piedra colorada, por la greda colorada en que se cria, ó está oculta, y molido el guiparo (sic), ó pedazo, es sal blanca; fuera de este serro, ay mas sal; en este valle hubo vna ciudad poblada de los Españoles conquistadores, que llamaron Nuestra Señ $o^{\text {ra }}$ de Guadalupe de la

murió en el poblado de Sagrado Corazón de chiquitos el 19 de agosto de 1763, el vizcaíno Francisco Ugalde, muerto en Piquete, Salta, el 6 de octubre de 1756 y a jesuitas anteriores a la fundación del colegio de Tarija, como Gaspar Osorio Valderrábanos, natural de Castrillo de Villavega, Palencia, que murió en el Chaco el $1^{\circ}$ de abril de 1639, a los italianos que también murieron en el Chaco Antonio Ripari el 1 de abril de 1639 y a Juan Antonio Solinas el 27 de octubre de 1683 (Storni, 1980).

${ }^{21}$ Sobre estas reducciones ver Page (2013, pp. 193-228).

${ }^{22}$ El P. José Francisco de Arce nació, como dijimos, en Santa Cruz de la Palma en Tenerife el 8 de noviembre de 1651 (según Baptista) o el 30 de julio de 1652 (según Storni), ingresando a la Compañía de Jesús de la provincia de Castilla a los 17 años para seguir sus estudios en Salamanca y terminarlos en Córdoba (Argentina) donde fue profesor de Filosofía. Llegó a Buenos Aires en la expedición del P. Cristóbal Altamirano de 1674, obteniendo el sacerdocio del obispo del Tucumán Francisco de Borja y Miguel en 1677. Destinado a las misiones guaraníticas, profesó su cuarto voto en el pueblo de San Ignacio, aunque luego fue trasladado a Bolivia, donde fundó los pueblos de Presentación y San Ignacio de Tariquea de chiriguanos y San Javier de chiquitos. Por ese tiempo junto a los chiquitos defienden la región de ataques bandeirantes. Tiene una muerte violenta por parte de los payaguás en el Lago Mandioré en el Matto Grosso do Sul, en diciembre de 1715, mientras buscaba al P. De Blende que también fue muerto. (Storni, 1980, p. 19 y Baptista, 2001, pp. 218-219). Una amplia bibliografía se origina a partir de Fernández (1895, I, pp. 22-26 y II, pp. 109-141).

${ }^{23}$ Efectivamente con la autorización del provincial Gregorio Orozco fundó la reducción de San Javier el 31 de diciembre de 1692, a pesar de la oposición de los españoles de Santa Cruz, que apresaban a los chiquitos para venderlos como esclavos.

${ }^{24}$ Esta estancia se formó cuando era superior de chiquitos y chiriguanos el P. Zea, que reemplazó al mencionado P. Arce y rector de Tarija el P. Diego Ruiz. Fue decisión del provincial P. Lauro Núñez, que el usufructo de una estancia del colegio de Tarija fuera para los chiriguanos, prometiéndoles que les enviaría 2.000 cabezas de ganado vacuno. Paralelamente se hizo otra estancia para el colegio en el Valle de Romero (Page, 2013, pp. 207-208). 
nueva vega de granada ${ }^{25}$; duro su poblacion solo 18 años, los chiriguanos con sus hostilidades obligaron á despoblarla, y recogerse los pocos españoles, que avia, a Tarija; en essa estancia tuvieron los Pueblos de chiquitos mucho ganado bacuno par aviarse de carne, y mulas par ${ }^{\mathrm{a}}$ el tragin; en Tarija tenían su Procurador y todos los sujetos, que iban á esos Pueblos, iban por Tarija, y venían a Tarija como que ese colegio era el $\mathrm{P} a d r^{\mathrm{e}}$ y superior de essas missiones de chiquitos; el marquez de Toxo no estaba contento solo con socorrer a los Pueblos de chiquitos; quizas, que se instose de nuevo la conveniencia de los Chiriguanos, y el año de 15 con abios, que dio, y vna bella imagen de bulto de la congregación de Nuestra Seño ${ }^{\text {ra }}$, se formo Pueblo en el valle de tariquea, en el citio antiguo, desde ese año se mantiene esse Pueblo, mudando varios citios, y valles, por las hostilidades de los Chiriguanos; quienes rompieron guerra, el año 27 de este siglo, dieron mucho que hazer á los españoles de Tarija, de Pomabamba y San ${ }^{\text {ta }}$ Cruz; en estas guerras ${ }^{26}$ sirvieron de capellanes de los españoles varios Jesuitas; y de soldados, los indios chiquitos, quienes por su lado contuvieron al enemigo chiriguano ${ }^{27}$; pasados 5 años de guerras, é inquietudes, 3 Jesuitas del colegio de Tarija con la cruz en la mano, perdiendo el vno la vida, y los dos viéndose en peligros de perderla, y el vno viendose ya despojado de la sotana con violencia ${ }^{28}$, apaciguaron, y bolbieron á poblar el valle de las salinas, que avia quedado del todo despoblado, con otros valles comarcanos, quedando casi la misma villa de Tarija, de frontera, y [2v] á peligro proximo de ser invadida desde el año de 27 hasta el de 41, en que llevando de capellan á vn Jesuita del colegi $i^{\circ}$ de tarija 300 hombres, hizieron un fuerte, ó recinto de palos puestos de pie, y en el quedo vn capitán con 50 hombres; y al año siguiente dos Jesuitas hizieron en dicho valle de Salinas vn fuerte de tapia con 9 peones conchabados; 9 leguas distante del recinto de palos de los españoles, quienes á exemplo de los Jesuitas hizieron vn fuerte mas capaz de adobe y se asseguraron mas; y los Jesuitas missioneros asseguraron a los chiriguanos christianos; passandolos de tariquea a las salinas, al abrigo del fuerte, que hizieron, donde han estado hasta este arresto dos jesuitas cuidando, y doctrinando á los chiriguano ${ }^{\mathrm{s}}$ christianos $^{29}$, con la rebelión dicha de los chiriguanos del año de 27 se destruyo el ganado de los chiquitos, y cerro el camino de tarija por el valle de salinas á los chiquitos, y corto del todo el comercio, y trasporte de los sujetos por Tarija á chiquitos, y solo quedo camino por Potosí, Chuquisaca y San ${ }^{\text {ta }}$ Cruz á chiquitos; se mudo el assiento de su Procurador á Potosi de donde les iban los

\footnotetext{
${ }^{25}$ El $1^{\text {o }}$ de noviembre de 1614 el virrey del Perú, marqués de Montes Claros, expidió en el puerto del Callao (Perú), la Real Cédula aceptando la propuesta de Juan Porcel de Padilla, quien se comprometía a conquistar el Valle de Las Salinas. De tal manera, la ciudad fue fundada en 1616 por Porcel de Padilla, denominándola Vega de Granada en homenaje a la ciudad ubicada en el centro de la provincia de Granada en España, de donde era oriundo, al igual que su esposa con quien viajó a Lima, aunque después contrajo matrimonio con una rica heredera llamada Juana de Vilela. Las tierras las había heredado del fundador de Tarija, Luis de Fuentes y Vargas. La población contó en su inicio con 60 españoles, además de numerosos indios y algunos esclavos. Pero sufrió varios ataques de los chiriguanos hasta que se abandonó, aunque 118 años después se refundó (Rivera Miranda, 2015).

${ }^{26}$ El alzamiento chiriguano efectivamente comenzó en 1727, encabezado por el cacique Juan Bautista Aruma, ex neófito de los dominicos de Chiquiatá. La rebelión duró varios años.

${ }^{27}$ Escribe el P. José Jolís (1972, 258, pp. 260-262) en el exilio, que el virrey del Perú, marqués de Castelfuerte (1724-1736), dio la orden al presidente de la Real Audiencia para enviar un cuerpo de tropas que castigó con éxito a los rebeldes en dos entradas. Fueron de capellanes de la expedición de 1728 comandada por el gobernador Armagosa, los PP. Jaime de Aguilar y Francisco Lardín. Mientras que capellanes de la segunda expedición del año siguiente fueron los PP. Ignacio de la Mata y Bartolomé Mora, siendo este último quien escribió una relación sobre la campaña (Page, 2013, p. 212).

${ }^{28}$ El que perdió la vida fue el P. Julián Lizardi, el que quedó semidesnudo fue el P. José Pons y el tercero fue Ignacio Chomé (Page, 2013, p. 214).

${ }^{29}$ Los dos jesuitas de Rosario de las Salinas que se hallaban para la expulsión fueron los PP. Simón Hernáez y Ramón Salat (Page, 2011, p. 121).
} 
socorros, y adonde sacaban sus efetos de sera, y lienzo, y algunas otras menudencias; no por esso perdió el coleg $i^{\mathrm{O}}$ de tarija la gloria de $\mathrm{P} a d r^{\mathrm{e}}$ de essas floridas missiones de chiquitos, ni la casa de yabí, ó marquezado de toxo de ser su fundador; en estos años atras les embio 9 calizes bellos de plata dorados, de nueva forma, todos de vna mano primorosa á los 9 Pueblos; á cada vno el suyo de regalo; y el Padr del Marquez presente avio al Padr $r^{\mathrm{e}}$ Agustin Castañares ${ }^{30}$ par $^{\mathrm{a}}$ la nueva mission de los Mataguayos, ofreciendole ser Patron, y aviados en vn todo del primer Pueblo, que fundase pero el Señ ${ }^{\text {or }}$ se contento con la oferta del Marquez, y del zelo del $\mathrm{P} a d r^{\mathrm{e}}$, permitiendo á los indios Abuchetas que le matasen luego, al empezar á poner los cimientos, aviendole recebido de buenas, y prometido de hazerse christianos; le mataron á 15 de septiembr de 1744, como se ha dicho, coronandole por mano de estos infieles, aviendole librado muchas vezes no sin particular providencia de manos de otros infieles en las missiones de los chiquitos, en quienes trabajo por 26 años, sacando gentes nuevas de los bosques, y fundo el Pueblo de San Ygnacio de los zamucos, y se vio en otros peligros en el descubrimient ${ }^{\circ}$ del camino del Paraguay á chiquitos, descubrimiento muy deseado y procurado de los missioneros de chiquitos, en cuya demanda murieron los referidos Padres Bartholome Blende, y Joseph Arze en manos de los infieles Payaguas, de cuyas manos se libro el Padr $r^{\text {e }}$ Agustin el año de 41, y el de 44 murió en lo de los Abucheta; su cadaver, aunque se solicito, no se le pudo encontrar, porque quan ${ }^{\text {do }}$ se pudo solicitar, avian passado casi diez meses; el cadaver del Padr $r^{\mathrm{e}}$ Julian Lizardi, como se pudo solicitar luego, se le encontro en el campo lleno de saetas, se traxo al Colegio de Tarija, donde está depositado en vna arca, y lugar sagrado ${ }^{31}$.

Los [3] sujetos, que ordinariamente se mantenian en este Colegi ${ }^{\circ}$, eran de diez á doze assi par ${ }^{\mathrm{a}}$ la instrucción ${ }^{\mathrm{n}}$, y enseñanza de los niños, como $\mathrm{p}^{\mathrm{a}}{ }^{\mathrm{a}}$ los varios ministerios pertenecientes al bien espiritual no solo de los vecinos de dicha Villa de tarixa, sino de toda la Provinci $^{\mathrm{a}}$ de Chichas, de Sinti y de fines que son otras 2 Provincia $^{\mathrm{s}}$, corregimientos en quienes empleaba sus missioneros, y missiones el coleg $i^{\circ}$ de Tarija. Para lo $1^{\circ}$ tenia este Colegio un sugeto destinado par $r^{\mathrm{a}}$ la escuela de niños, y otro $\mathrm{p} a r^{\mathrm{a}}$ enseñar la gramatica, y latinidad; una, y otra eran sumamen ${ }^{\text {te }}$ necesar $i^{\text {as }}$ como las unicas, que havia en toda la Villa, y á una, y otra concurrian no solo los niños de tarixa, y sus contornos, sino aun de otras partes remotas de dicha Provinci ${ }^{\mathrm{a}}$ Fuera de los dos sugetos destinados par ${ }^{\mathrm{a}}$ esto havia otros dos destinados par ${ }^{\mathrm{a}}$ hazer Mission en toda la Provinci ${ }^{\mathrm{a}}$ que es bien dilatada: á esta salianlos dos sujetos dos vezes al año, y en cada salida se estavan ya los a, y a los 9 meses, [3v] por ser mucha la gente, tanto que en los dos años ultimos passaron de 22000 comuniones las que se contaron en dichas missiones, casi todas de Indios pobres, é ignorantes, en quienes es necesari ${ }^{\circ}$ que el Missionero á costa de mucha paciencia se muestre superior al insoportable trabajo, que se le ofrece. Dichas Missiones son summamen ${ }^{\text {te }}$ necesarias, porque estando, como estan, las gentes no en Pueblos formados, como en la Europa, sino esparcidos por los valles, y campaña, aun quando los Curas de los distritos tengan algun zelo, y quieran cumplir con su deber, no es posible por las mucha distancias, y fragosidad del terreno, y por esto se haze necesario, que los Missioneros á costa de indecible trabajo socorran á los infelices con la instrucción ${ }^{\mathrm{n}}$, y demás ministerios propios de un Missionero.

\footnotetext{
${ }^{30}$ Sobre el P. Castañares escribió una biografía el P. Juan de Montenegro publicada en Madrid en 1746 con el título: Breve noticia de las misiones, peregrinaciones apostólicas, trabajos, sudor y sangre vertida en obsequio de la fe, del venerable padre Agustín Castañares de la Compañía de Jesús, insigne misionero de la provincia del Paraguay en las misiones de chiquitos, zamucos y últimamente en la Misión de los infieles mataguayos (Furlong, 1964, pp. 51-101).

${ }^{31}$ Sobre la vida de Lizardi hay una amplia bibliografía específica (Lozano, 1741. Leonhardt, 1935, pp. 92103 y Vaughan, 1901, entre otros).
} 
Fuera de la Mission de toda la Provinci ${ }^{a}$ de Chichas tenia el Colegio de tarixa á su cargo el embiar cada tres años dos Missioneros á la Villa de Pica ${ }^{32}$, y otros Pueblos comarcanos en la costa de la mar del Sur distantes de tarixa 200, y aun mas leguas, lo mas de dicho camino es por despoblados, y por la cordillera de Lipes summamen $n^{\text {te }}$ fría, y por otros Partes notablemen ${ }^{\text {te }}$ aridos. La Villa de Pica, y sus Pueblos comarcanos pertenecen al obispado de Arequipa, pero por estar retirados, y bien necesitados de las tareas evangelicas, pidió á los Superiores de nuestra Provinci ${ }^{a}$ del Paraguay un piadoso Cavallero, llamado Don Joseph Basilio de la Fuente ${ }^{33}$, le hiziessen el favorde embiar cada tres años dos Missioner ${ }^{\mathrm{os}}$, que evangelizassen en aquellos Pueblos, ofreciendose dicho Cavallero á dotar, como dotó, dicha Mission ${ }^{34}$ y desde entonces han ido siempre cada tres años dos Missioneros a dichos Pueblos con notable fruto de sus habitadores, y con igual fruto se comenzaron á dar en ellos el año de 67, que fue el ultim ${ }^{\circ}$, en que fueron los Padr $r^{\text {es }}$ Missioner $^{\mathrm{os}}$, los exercici $^{\mathrm{os}}$ de San Ignaci ${ }^{\mathrm{O}}$. A mas de la Mission del Partido tenia el Colegi $i^{\mathrm{O}}$ de tarixa otros [4] varios ministerios enderesados á instruir á los proximos, y á imprimir en sus corazones el $\mathrm{S}{ }^{\text {to }}$ temor de $\mathrm{Dio}^{\mathrm{s}}$ estava entablada la Congregació ${ }^{\mathrm{n}}$ de la buena muerte, en que se platicava, y hazian los exercicio ${ }^{\mathrm{s}}$ propios de dicha Congregació $o^{\mathrm{n}}$ una vez cada semana: itt. La Congregación ${ }^{\mathrm{n}}$ de los Santos Corazones de Jesus, y Mari ${ }^{\mathrm{a}}$, en que se platicava, y se hazian los exercicio ${ }^{\mathrm{s}}$ proprios de dicha Congregación ${ }^{\mathrm{n}}$ los $1^{\text {os }}$ Viernes de cada mes, y con mas especialidad el Viernes inmediato á la Octava del Corpus, y el Domingo $\operatorname{sig}$ ien $^{\text {te }}$ se hazia su fiesta con missa y sermon, y con la maior solemnidad posible.

Assi mismo se hazian las fiestas del Dulce nombre de Jesus, las 40 horas, los Dolores, y

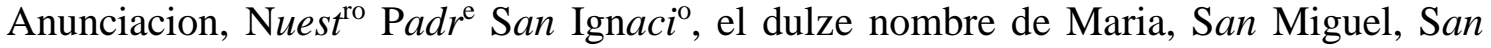
Francis ${ }^{\mathrm{co}}$ Xavier, y los 4 Jubileos del año, en que havia Platica por la tarde. En la Quaresma havia los Domingos sermon de Historia, precediendo por modo de salutacion explicacion de algun punto de doctrina, y al fin algun discurso moral sobre el punto de la historia; los miercoles, y Viernes havia exemplo, y el Viernes S $a n^{\text {to }}$ la funcion de la agonía. El dia 15 de Agosto se hazia con solemnidad la fiesta á Nuest ${ }^{\mathrm{ra}} \mathrm{Señ} o^{\mathrm{ra}}$ de tariquea; fue esta $S a n^{\text {ta }}$ Imagen la $1^{\text {a }}$, que sirvio en la Dedicacion de la Iglesia de la Mission de los Indios chiriguanas, y quando estos infieles invadieron la Mission, y mataron á su Missionero el Padr $r^{\mathrm{e}}$ Julian Lizardi el año de 735, flecharon á esta San ${ }^{\text {ta }}$ Imagen, y aviendole cortado la cabeza, la arroparon lexos del cuerpo; despues un piadoso vezino sin reparar en el peligro de que lo matassen los barbaros, hizo exquisitas diligencias hasta que aviendo encontrado en un parage el cuerpo flechado, y en otro distante la cabeza de la $\mathrm{S} \mathrm{n}^{\text {ta }}$ Imagen, traxo uno, y otro, y con- $[4 \mathrm{v}]$ curriendo el Cabildo, y vecindario de tarixa se entró en triunfo la San ${ }^{\text {ta }}$ Imagen, y se colocó en la Iglesia de Nuest ${ }^{\text {ro }}$ Colegio, haciendosele por entonces una solemne fiesta de desagravios, luego con las limosnas, que se

\footnotetext{
${ }^{32}$ La Villa de Pica era territorio indígena ubicado sobre el Camino del Inca, entre los tambos de Huatacondo al sur y Mamiña al norte. Cuando pasó Diego de Almagro en 1535 fueron atacados, pero igualmente se instalaron en 1556 y repartieron encomiendas. Pica fue sede del Tenientazfo de Tapacará, que dependió del corregimiento de Arica. La primera familia castellana en afincarse fueron los Ceballos que establecieron una hacienda cuyo producto principal fue el vino.

${ }^{33}$ José Basilio de la Fuente y Haro fue un poderoso minero de la región de Tapacará, donde residía. Era descendiente de los descubridores de Huantajaya y además de poseer grandes riquezas en minas y haciendas era muy generoso y propagador de la devoción de la virgen del Carmen. Construyó a su costa la iglesia de Tarapacá y se casó con doña María Jacinta de Loaisa, hija del coronel Bartolomé Loaisa, a su vez importante minero (Page, 2011, p. 267)

${ }^{34}$ El convenio fue rubricado por don José Basilio y por el Padre rector de Tarija, que era el P. Antonio Miranda, en marzo de 1759, y en esta forma quedó entablada la misión de Pica y Tarapacá (Page, 2011, p. 272)
}

130 Carlos A. Page. Francisco Fabra y su relación del colegio de Tarija y sus ... 120-134. 
recogieron de algun ${ }^{\text {as }}$ piadosas personas se dotó, y se ha continuado, precediendo una devota Novena, y los tres días antes de la fiesta se predica sermon moral, ó de Mission par $^{\mathrm{a}}$ disponer los animos para las misas, confesion ${ }^{\mathrm{es}}$ y communion ${ }^{\mathrm{es}}$ del dia siguien ${ }^{\mathrm{te}}$ en que se celebra la fiesta, y por la tarde con assientencia de los Militares de la Jurisdic ción ${ }^{\mathrm{n}}$, cabildo y Vecindario sale la Procesion, cantandosele devotamen ${ }^{\text {te }}$ el San ${ }^{\text {to }}$ Rosario á Nues$t^{\mathrm{ra}} \mathrm{Seño}{ }^{\mathrm{ra}}$.

No solo este dia, sino todos los días de fiesta clasicos, y aun algun ${ }^{\text {os }}$ no tan solemnes del año, como también en el tiempo de Quaresma era notable el concurso á nuestra Iglesia por causa de que en otras Iglesias apenas havia quien confessara á la gente, pues en la Matriz apenas havia clerigo, que lo pudiesse hazer, en San Agustin ordinariamen ${ }^{\text {te }}$ era solo el Padr $r^{\mathrm{e}}$ Prior, lo mismo en San to Domingo, y solo en San Francis ${ }^{\mathrm{co}}$ havia algun despacho, pero lo mas del vecindario venia a Nuest ${ }^{\text {ra }}$ Iglesia. De aqui resultava otra tarea bastante pessada $\mathrm{p}^{\mathrm{a}}{ }^{\mathrm{a}}$ los sugetos de Nuestro Colegio, y eran las salidas muy frequentes de dia, y de noche á las confessiones de enfermos, y asistencia de los moribundos, pues par ${ }^{\mathrm{a}}$ casi todos acudian á nuestro Colegio, sabiendo, quan prontos estaban siempre los Jesuitas par ${ }^{\mathrm{a}}$ este ministerio. Ni era de menor trabajo la tarea de los Exercici ${ }^{\mathrm{os}}$ de Nuestro Padr $r^{\mathrm{e}}$ San Ignaci ${ }^{\mathrm{o}}$, que anualmen ${ }^{\mathrm{te}}$ se daban á personas de ambos sexos, pues ordinariamen ${ }^{\text {te }}$ passaban de 300 , las que anualmen ${ }^{\text {te }}$ entraban en distintas semana á hazerlos, para cuio fin avia el Colegi $i^{\circ}$ comprado casa, con bastantes aposentos, pero por ser aun estos pocos, ultimamen ${ }^{\text {te }}$ se avia comprado otra casa contigua $a r^{\mathrm{a}}$ dar mas capacidad á la que antes tenia. Es indecible el fruto, que no solo en tarixa, sino en todas aquellas Provincis ${ }^{\text {as }}$ de la America se [5] experimentava con estos $\mathrm{San}^{\text {tos }}$ exercicios tanto, que si en todas partes se juzgan útiles, por allá son necesarios $\mathrm{p}^{\mathrm{a}}{ }^{\mathrm{a}}$ contener las passiones, arreglar las vidas, y mantener las gentes en el San ${ }^{\text {to }}$ temor de Dio ${ }^{\text {s }}$. Con estos San ${ }^{\text {tos }}$ Exercici $^{\text {os }}$ se atajaban los vicios, crecia la frequencia de sacramentos, y se conocía palpablemen ${ }^{\text {te }}$ el fruto, que de ellos se sacaba.

Para todos estos ministerios, fuera de los dos Mission $e^{\text {ros }}$ del Partido, y Maestros de Escuela, y Gramatica tenia el Colegi $i^{\circ}$ tres, ó quatro sujetos operarios, que atendiessen á las confesiones, sermones de Nuest ${ }^{\text {ra }}$ Iglesia, y de otras, par ${ }^{\mathrm{a}}$ los quales convidaban las personas, que hazian la fiesta. De modo que ordinariamen ${ }^{\text {te }}$ eran unos diez los sugetos, que havia en este Colegi $i^{\circ}$ fuera de los dos, que estaban en la Mission de los Indios Chiriguanas distante como unas treinta leguas de tarixa, y en la que (segun la buena disposicion en que parece, que estaban los Indios de la Cordillera) se comenzavan a tener esperanzas bien fundadas de que havia presto copiosa, sazonada mies para las tropas del Señ ${ }^{\text {or }}$ de todo lo qual dara particular razon el sugeto Missionero, que estava encargado de dicha Mission.

Para el sustento, y manutencion de los sujetos, aunque á los principios se pasaba con alguna penuria, por ser cortos los fondos del colegi $i^{\mathrm{o}}$, concurrian con limosnas algunas personas acomodadas: despues huvo ya bienechores, que viendo el mucho fruto, y grande utilidad, que se requeria á la Villa de tarixa, y Provinci ${ }^{a}$ de Chichas, de que huviesse Jesuitas en ella, dieron par $r^{\mathrm{a}}$ el Colegi $i^{\mathrm{o}}$ dos haciendas, una par ${ }^{\mathrm{a}}$ tener ganados, y otra que consistía en una viña, á las quales se añadió otra hazienda de Viña, y algunas tierras de pan llevar, que se compró; con lo qual quedó sufficientemen ${ }^{\text {te }}$ fundamentado el Colegi ${ }^{\circ}$ par $^{\mathrm{a}}$ una decente manutencion de los Sugetos ${ }^{35}$. Los Criados con que se cuidaban estas haciendas eran de tres maneras, unos asalariados en la forma comun, que se estila [5v] por aquellos países; los otros son Indios Yanaconas, los quales par $r^{\mathrm{a}}$ que sean instruidos

${ }^{35}$ Sobre las haciendas del colegio de Tarija ver Presta (1996, pp. 179-198). 
en la fe, y buenas costumbres y $\mathrm{pr}^{\mathrm{a}}$ facilitar mejor el que paguen al Rey sus tasas, como para que no se anden vagamundos y sin trabajar, los tiene adjudicados $\mathrm{S} u$ Magesta ${ }^{\mathrm{d}}$ á vezinos nobles, y á Comunidades Religiosas, para que se sirvan de ellos, y los amos paguen por ellos las tasas, esto es por los Varones desde los 18 hasta los 65 año $o^{s}$ de su edad, que ya en esta edad cesan de pagarlas. Estas tasas son en unos (segun la nacion, de que descienden) de tres peso y medio fuertes, en otros de 7 , y en otros de 8 peso $o^{\mathrm{s}}$ y 3 reale $^{\mathrm{s}}$ de plata, las quales tasas se pagan anualmen $n^{\text {te }}$ al Corregid ${ }^{\text {or }}$ o su thenien ${ }^{\text {te }}$ segun la lista, que se haze todos los años, en lo qual se experimenta una nota de ventaja par ${ }^{\mathrm{a}}$ las caxas reale ${ }^{\mathrm{s}}$, pues para cobrar de los Indios libres, que no estan assi adjudicados, cuesta summo trabajo, porque quando llega el tiempo de la paga, se huien por temor de que los opriman, y pongan en la cárcel, como se ve todos los añ $o^{\mathrm{s}}$, lo que no sucede con los que tienen amo, ó dueño, a quien servir, pues aunque el Indio se huia, se le cobra a su amo la tassa.

Fuera de esto se le da al Indio Yanacona anualmen ${ }^{\text {te }}$ ropa, con que vestirse, y cada mes se le da su racion de carne, y maíz par comer: las Mugeres, y sus hijas comúnmente no sirven al amo, y por esso á estas no se les da racion, pero se le da al Indio un retazo de tierras $\mathrm{p}^{\mathrm{a}}{ }^{\mathrm{a}}$ sembrar, un par de bueyes, reja, y arado, para que pueda mantener á su familia; si estan enfermos, se les assiste con las medicinas, y medico, que ofrece el Pais, y para que esten assistidos cabalmen ${ }^{\text {te }}$ aun en lo espiritual, tienen formada en el Colegi $i^{\mathrm{o}}$ una Congreg $a c i o^{\mathrm{n}}$ con su Prefecto, ó Capellan, que les platica, y explica la doctri ${ }^{\text {na }}{\text { christi } i{ }^{\text {na }}}$ los Domingos, y zela, que vivan bien, y no den escandalos. En esta misma Congregación ${ }^{n}$ estavan alistados los esclavos, que son la $3^{\text {a }}$ especie de criados, ó sirvientes, que tenia el Colegi $i^{\mathrm{O}}$ aunque estos eran pocos en tarixa, por tener Yanaconas, y [6] á los quales se les vestia, se les dava de comer, y assistia en sus enfermedades, como se ha dicho de los Yanaconas.

El producto de las haciendas del Colegi ${ }^{\circ}$, aunque no era excesivo, como suelen algunos pensar, era lo bastante assi para la decente manutencion de los sujetos, como a proporcion de los sirvientes, fuera de que era no pequeño el gasto, que se hazia en la Mission del Partido, por ser la Provincia dilatada, y en los exercicios, que anualmen ${ }^{\text {te }}$ se daban, en los quales se procurava, que los exercitantes tuviessen una decente asistencia, para que assi nadie se desanimasse, y todos consiguiessen el fruto, que regularmen ${ }^{\text {te }}$ se experimentava. Despues de estos gastos eran pocas las limosnas, que el Colegi $i^{\circ}$ hazia; y si aun quedava alguna cosa resagada, se empleava en algunos ornamentos, y alajas para la Iglesia, de que estaba ya sufficientemente surtida.

De todos estos bienes, que experimentaban los vecinos de la Villa de tarixa con la estada, y assistencia en ella de los Jesuitas, se puede inferir, quan sensible seria par ${ }^{\mathrm{a}}$ todos su salida, y la perdida de tanto bien. Lo fue tanto, que no es facil decirlo en tan corta relacion: como testigo de vista, y aun de experiencia puedo assegurar, que fue universal el llanto de toda la gente, y en los dos messes, que me detuve en el Conven ${ }^{\text {to }}$ de San Francis ${ }^{c o}$ me asseguraron personas fidedignas, que en las casas estavan las gentes, como si huvieran muerto sus dueños sin querer hablar á los que las visitaban, desahogandose solamen ${ }^{\text {te }}$ con lloros, y suspiros; estos mismos se oian en la Iglesia de San Francis ${ }^{\mathrm{co}}$, mientras mis dos compañeros, y yo deciamos missa, y aunque la decíamos muy temprano, y al amanecer, se llenava la Iglesia de gente, como si fuera dia de Jubileo: y por lo que toca al consuelo de confessarse, decían varias personas acostumbradas a frequentar sacramen ${ }^{\text {tos }}$ en nuest ${ }^{\text {ra }}$ Iglesia, que pues faltavan los Jesuitas, no seria poco el confessarse por la Pascua. Esta es en breve la relacion llana, y sincera de tarixa. Mayo 10 de 1770.

Francis ${ }^{\mathrm{co}}$ Fabra 


\section{Referencias bibliográficas}

Baptista SJ, J. (2001). “Arce, José Francisco de. Misionero, víctima de la violencia”. En: O'Neill SJ, C. E. y Domínguez J. M. (directores). Diccionario histórico de la Compañía de Jesús: biográfico-temático. Volumen 1. Roma: Institutum Historicum Societatis Iesus, pp. 218-219.

Bussu, S. (2003). Mártires sin altar. Padre Juan Antonio Solinas, Don Pedro Ortiz de Zárate y dieciocho cristianos laicos. Salta: Universidad Católica.

Campero, R. M. (2008). El Marques de Yavi. Buenos Aires: ed. Catálogos.

Fernández, J. P. (1895). Relación historial de las misiones de indios Chiquitos que en el Paraguay tienen los padres de la Compañía de Jesús. 2 tomos. Madrid: Librería de Victoriano Suárez.

Furlong SJ, G. (1939). Entre los vilelas de Salta. Según noticias de los misioneros jesuitas... Buenos Aires: Academia Literaria del Plata.

(1964). Juan de Montenegro y su "Breve Noticia". Buenos Aires: Ediciones Theoria, pp. 51-101.

Jolís SI, J. (1972) [1789]. Ensayo sobre la historia natural del Gran Chaco. Estudio preliminar Ernesto J. A. Maeder. Resistencia: Universidad Nacional del Nordeste, Facultad de Humanidades, Instituto de Historia.

Leonhardt SI, C. (1935). "Padre Julián Lizardi, S.J. En el segundo centenario de su martirio", Estudios 52, pp. 92-103.

Lozano SI, P. (1741), Vida y virtudes de V. P. Mártir Julián de Lizardi. Salamanca: por Antonio Villagordo.

Page, C. A. (2007). El viaje de Europa a Buenos Aires en los relatos de los jesuitas de los siglos XVII y XVIII. Córdoba: Báez ediciones.

(2010). El Colegio de Tarija y las misiones de Chiquitos según las Cartas Anuas de la Compañía de Jesús. Raleig, Carolina del Norte: Lulu Press Inc.

(2011). Relatos desde el exilio. Memorias de los jesuitas expulsos de la antigua provincia del Paraguay. Asunción: Servilibro.

(2013). "La evangelización jesuítica entre los chiriguanos". Revista de Humanidades y Ciencias Sociales: Instituto de Investigaciones Económicas y Sociales “José Ortiz Mercado”, Seg. Época, Vol. 17, N 1-2, pp. 193-228.

Palomeque, S. y Tedesco. É. (2014). "Padrón de Casabindo y Cochinoca de 1654. Transcripción y estudio preliminar". Corpus, Archivos virtuales de la alterirdad amereicana.4(2).

Pastells SJ. P. y Matteos SJ, F. (1949). Historia de la Compañía de Jesús en la Provincia del Paraguay. T. VIII, segunda parte 1760-1768. Madrid: Consejo Superior de Investigaciones Científicas.

Presta, A. M. (1996). "Las propiedades del colegio de la Compañía de Jesús de Tarija". Anuario II Archivo y Biblioteca Nacionales de Bolivia, pp. 179- 198.

Rivera Miranda, E. (2015). La provincia O`Connor en la historia de Tarija. Tomo 1. Cercado: Grupo Editorial Kipus. 
Rossi, J. J. (2007). Los wichí. (“Mataco”). Colección Aborígenes de la Argentina. Buenos Aires: Galerna.

Storni SJ, H (1980). Catálogo de los jesuitas de la Provincia del Paraguay (Cuenca del Plata) 1585-1768. Roma: Institutum Historicum SI.

Vaughan, K. (1901). Descubrimiento de los restos del venerable P. Julián de Lizardi (de la Compañía de Jesús) y su translación de Tarija a Buenos Aires. Con la vida del mártir por el P. Pedro Lozano, S.J. Buenos Aires: Librería de Subirana. 